\title{
The impact of COVID-19 pandemic outbreak on education and mental health of Chinese children aged 7-15 years: an online survey
}

Zhongren Ma', Sakinah Idris ${ }^{1,2}$, Yinxia Zhang ${ }^{1}$, Liu Zewen ${ }^{1}$, Amaad Wali ${ }^{3}$, Yunpeng $\mathrm{Ji}^{4}$, Qiuwei Pan $^{4}$ and Zulqarnain Baloch ${ }^{3^{*}}$ (D)

\begin{abstract}
Background: The emerging of psychological problems triggered by COVID-19 particularly in children have been extensively highlighted and emphasized, but original research in this respect is still lagging behind. Therefore, we designed this study to evaluate the impact of COVID-19 pandemic on mental health and the effectiveness and attitudes towards online education among Chinese children aged 7-15 years.

Methods: A detailed questionnaire, comprising of 62 questions was designed and parents or caretakers of 7 to 15 years old children were invited to participate via WeChat, a multi-purpose messaging, social media and mobile payment app, which is widely used by the Chinese population. A total of 668 parents across different regions of China were included.

Results: During COVID-19 pandemic, 20.7 and 7.2\% children report experiencing post-traumatic stress disorder (PTSD) and depressive symptoms due to the COVID-19 pandemic. PTSD and SMFQ-P scores are significantly higher in middle school and boarding school students compared to primary and day school students. Multiple logistic regression analysis revealed that school system and province of origin are factors significantly associated with developing PSTD symptoms. $44.3 \%$ respondents feel online education is effective in gaining knowledge and improving practical and communications skills. $78.0 \%$ believe the online education system is efficient. Overall 79.8\% respondents are satisfied and children can adapt to this new education system. During the COVID-19 pandemic, we found 1 in five children have PTSD and 1 in 14 children have depressive symptoms.

Conclusion: In summary, COVID-19 epidemic has caused PTSD and depression symptoms among Chinese children aged 7 to 15 years. In general, a large proportion of respondents are satisfied with online education, but still a substantial proportion of students are not comfortable with this new form of learning. Authorities should optimize online education systems and implement effective interventions to cope with the psychological effects of COVID-19 on children, as it is affecting the global population and remains uncertain when it will end.
\end{abstract}

Keywords: COVID-19, Mental health, Online education, Children, China

\footnotetext{
* Correspondence: znbalooch@yahoo.com

${ }^{3}$ Faculty of Life Science and Technology, Kunming University of Science and Technology, Kunming 650500, Yunnan, China

Full list of author information is available at the end of the article
}

(c) The Author(s). 2021 Open Access This article is licensed under a Creative Commons Attribution 4.0 International License, which permits use, sharing, adaptation, distribution and reproduction in any medium or format, as long as you give appropriate credit to the original author(s) and the source, provide a link to the Creative Commons licence, and indicate if changes were made. The images or other third party material in this article are included in the article's Creative Commons. licence, unless indicated otherwise in a credit line to the material. If material is not included in the article's Creative Commons licence and your intended use is not permitted by statutory regulation or exceeds the permitted use, you will need to obtain permission directly from the copyright holder. To view a copy of this licence, visit http://creativecommons.org/licenses/by/4.0/ The Creative Commons Public Domain Dedication waiver (http://creativecommons.org/publicdomain/zero/1.0/) applies to the data made available in this article, unless otherwise stated in a credit line to the data. 


\section{Backgrounds}

The consequences of the ongoing coronavirus disease 2019 (COVID-19) pandemic is infiltrating in every aspects of our society and daily lives. However, what is the effectiveness and draw-backs of these control measures and how the pandemic will eventually remain largely uncertain. According to United Nation estimates, 188 countries have enforced nationwide school closures, resulting in more than $90 \%$ enrolled students are out of school and confined at home [1]. School closure, living in isolation, and fearing risk of the infection are expected to have major impact on education, psychological health, and well-being of children [1]. Epidemiological evidence suggests that approximately $5-12 \%$ of people may develop post-traumatic stress disorder (PTSD) after a traumatic event [2]. The emerging of psychological problems triggered by COVID-19 particularly in children have been extensively highlighted and emphasized, $[3,4]$ but original research in this respect is still lagging behind.

In response to the COVID-19 outbreak, the Chinese Government was the first to order nationwide school closure as an emergency measure to minimize the risk of spreading $[4,5]$. The Ministry of Education estimates that more than 220 million children and adolescents are confined to their homes. This includes 180 million primary and secondary students and 47 million preschool children [4]. To minimize educational losses, immense efforts were made from different stake holders to create online courses and deliver them through electronic media and internet [5]. As China has experienced the first wave of the epidemic and the children were confined at home for the longest period two or more months, it is an ideal setting for comprehensively evaluating the impact of COVID-19 pandemic controlling measures on education and mental health of the children. Current study was design to assess the effects and attitudes towards online education, the prevalence of PTSD and depression symptoms, and their associated factors among children aged 7 to 15 years.

\section{Methods}

We conducted a cross-sectional survey from April 11th to 17 th, 2020. The survey involved a questionnaire that was distributed through online version via WeChat, a Chinese multi-purpose messaging, social media and mobile payment app. It is widely used in China with monthly active users estimated of one billion. Parents or caretakers of 7 to 15 years old children were invited to participate in this study. They are requested to involve their children to complete the survey together.

This study uses purposive sampling. A form containing the study questionnaire was distributed among specific social media groups comprising parents who have at least a child age between 7 and 15 years old and who also follow the online education. Messages were sent to them to ensure the appropriate selection of study participants. A friendly reminder was sent to potential respondents to ensure the highest possible response rate. Participants were not aware of the study aim or outcomes to reduce the risk of any possible bias. The questionnaire was self-administered without intervention by the authors or any specific person, and it did not contain any identifying data of the participants to ensure confidentiality. Questionnaires with incomplete information or missing data were excluded from the analysis.

\section{Survey instrument}

A detailed questionnaire, comprising of 62 questions was designed in both English and Chinese languages, and the Chinese version was used in this study. The questionnaire comprised of 15 basic demographic characteristics, such as children's gender, age, their education as well as data about their parent's marital status, level of education, profession, and income. The questionnaire also addressed the usability for online education of the children in three aspects; (1) the effectiveness, means the accuracy and completeness in which the child get the knowledge (3 questions), (2) the efficiency, to measure through task/homework completion (3 questions), and (3) satisfaction, means the comfort and acceptability of online education (2 questions). Each question comprises of five options ranging from 1-not at all, 2- a little bit, 3moderately, 4-quite a bit, and 5 -extremely. Several questions related to the online education is our primary outcome.

Additionally, the survey also included two mental health assessments that measure level of anxiety and depression which is our outcome variables.

The psychological impact was evaluated using a validated scale, i.e. Impact of Events Scale-Revised (IES-R) $[6,7]$. IES is a self-reporting measure used to assess the response to a specific stressful life event [8]. It is composed of 22 items, each with a Likert rating scale from 0 to 4 ( 0 not at all; 1 a little bit; 2 moderately, 3 quite a bit; 4 extremely). The maximum score is 88 . A higher score indicates a greater concern for PTSD. IES-R has been translated in Chinese. The reliability and validity have been extensively demonstrated [9]. It is frequently used in trauma research worldwide [10, 11].

The SMFQ-P [12] is a 13-item shortened version of the 33-item MFQ [13]. It was developed in response to the need for a brief depression measure to reduce participant burden in research trials, while still retaining strong criterion validity [12]. Responses are rated on a 3point scale $(0=$ not true, $1=$ sometimes, and $2=$ true $)$. The SMFQ-P has matched versions completed by the parent (SMFQ-P) and is freely available [13]. The SMFQ-P takes approximately 3 to $5 \mathrm{~min}$ to complete 
and has been validated with clinical [14] and nonclinical $[12,15]$ samples. A score 12 or above was commonly used to indicate clinically significant depression. The MFQ was originally designed for use with children. It is based on DSM-III-R (stands for Diagnostic and Statistical Manual of Mental Disorders) symptom criteria and has been recommended by National Institute for Health and Clinical Excellence (2005) for the screening of depression in children and adolescents.

\section{Statistical analysis}

Descriptive and inferential statistics were calculated using SPSS version 20.0 for Windows (SPSS Inc., Chicago IL). Descriptive statistics analysis was done to demonstrate the demographic characteristics of the participants. A univariate analysis was first examined to screen statistically significant variables to be included in multivariate logistic regression analyses. The estimations of the strengths of associations were revealed by the odds ratio $(\mathrm{OR})$ with a $95 \%$ confidence interval (CI). All statistical tests were two-sided and a $p$-value $<0.05$ was considered as statistically significant. We performed all statistical analyses using (IBM) SPSS version 22.0.

\section{Ethical approval}

The protocol used in this study was in accordance with the Declaration of Helsinki and was approved by the Ethics Committee at Northwest Minzu University Lanzhou, China. Informed consent was individually obtained from the parents.

\section{Results}

In total, 680 individuals from 27 provinces, autonomous regions and municipalities across China were invited to participate in the survey by filling the questionnaires. 12 declined to continue the survey, resulting in 668 participants with children aged 7-15 years finally included in the study. Detailed demographic characteristics of the children and their families are presented in Table 1. Majority participants are from Henan (34.6\%), Gansu (25.0\%), Inner Mongolia (10.8\%), Liaoning (9.3\%) and Zhejiang (8.1\%) provinces and the remaining are from 22 other provinces, autonomous regions or municipalities across China. Majority participants are day school students $(87.1 \%)$, and $95.5 \%$ lived with parents In terms of ethnicity, $87.7 \%$ are Hans and $12.3 \%$ are from other ethnicities. $75.4 \%$ live in urban areas and $24.6 \%$ have rural background (Table 1 ).

562 out of 668 respondents have reported that their families are well-aware of COVID-19. Overall, respondents think their children are affected psychologically (46.7\%), emotionally (35.8\%), socially (34.0\%) and physically $(27.4 \%)$ by the COVID-19 pandemic. In contrast, $37.4 \%$ think their children are not affected at all. $73.2 \%$ participants reported that their children have returned to normal routine after the control of COVID-19 in China (Appendix Table 6). Interestingly, 138 participants reported that their children are affected both physically and psychologically, and 67 reported to be affected physically, psychologically, socially and emotionally.

In this study, an IES-R score of $>20$ was used to estimate the prevalence of PTSD, and 20.66\% children have the score above 20 (Table 2). PTSD symptoms were significantly more prevalent in middle school $(p=0.05)$ and boarding school students $(p=0.004)$ compared to primary school and day school students, respectively. SMFQ-P score of $>12$ was used to estimate the prevalence of depression among children. 7.18\% students have the score above 12. SMFQ-P based depression was also significantly more prevalent in middle school $(p=0.032)$ and boarding school students $(p=0.02)$ compared to primary and day school students, respectively (Table 2).

44.3\% respondents feel online education is effective (scored as average, good or excellent), in terms of gaining knowledge and improving practical and communications skills. $78.0 \%$ think it is efficient that students can complete the assigned tasks, communicate with teachers and take advantages of the multimedia format. $78.0 \%$ responded that they are overall satisfied and children can adapt to the online education system (Table 3). Correlation analysis revealed that children age ( $p$-value $<$ $0.0001)$, school level ( $\mathrm{p}$-value $<0.0001)$, provincial $(p=$ $0.006) \mathrm{l}$ and residential background $(p=007)$, and family income status $(p=0.008)$ is significantly linked with the effectiveness and satisfaction of the online education system (Table 4). The total IES-R scores are significantly correlated with type of school $(\mathrm{p}=0.006)$, children living with whom $(p=0.044)$, and provincial background $(p=$ $0.016)$. The SMFQ-P scores are significantly correlated with child age $(p=0.004)$, school level $(p=0.10)$, school type $(p=0.001)$, provincial back ground $(\mathrm{p}=0.016)$ and area of residence $(p=0.032)$ (Table 4$)$.

According to univariate analysis, children education level (primary or middle school), school system (day or boarding school), living status, provincial background and father profession are significantly linked with PSTD symptoms. All these significant factors were further included into multiple logistic regression analysis. School system $(p=0.05)$ and provincial background ( $p=0.013)$ remain as the significant factors for developing PSTD symptoms in children (Table 5).

Univariate analysis revealed that school level (primary or middle school) and system (day or boarding school) are significantly associated with depression among children. However, both factors are not significant in multivariate logistic analysis (Appendix Table 7). 
Table 1 Demographic characteristics of the respondents $(n=668)$

\begin{tabular}{|c|c|c|c|c|c|}
\hline \multicolumn{3}{|l|}{ Child Demographics } & \multicolumn{3}{|c|}{ Parents Demographics } \\
\hline Characteristics & Frequency & Percentage & Characteristics & Frequency & Percentage \\
\hline Sex & & & Marital status & & \\
\hline Male & 336 & $50.3 \%$ & Married & 643 & 96.3 \\
\hline Female & 332 & $49.7 \%$ & Divorced & 25 & 3.7 \\
\hline Age (years) & & & Number of child & & \\
\hline 7 & 53 & 7.9 & Not filled & 19 & 2.8 \\
\hline 8 & 68 & 10.2 & 1 & 257 & 38.5 \\
\hline 9 & 90 & 13.5 & 2 & 339 & 50.7 \\
\hline 10 & 112 & 16.8 & $>2$ & 53 & 7.9 \\
\hline 11 & 51 & 7.6 & Mother education & & \\
\hline 12 & 20 & 3.0 & Not filled & 24 & 3.6 \\
\hline 13 & 50 & 7.5 & Illiterate & 8 & 1.2 \\
\hline 14 & 91 & 13.6 & Primary & 42 & 6.3 \\
\hline 15 & 133 & 19.9 & Middle & 176 & 26.3 \\
\hline School level & & & High school & 98 & 14.7 \\
\hline Primary & 394 & 59.0 & Diploma & 103 & 15.4 \\
\hline Middle & 274 & 41.0 & Undergraduate & 142 & 21.3 \\
\hline School type & & & Master & 49 & 7.3 \\
\hline Boarding school & 86 & 12.9 & $\mathrm{PhD}$ & 26 & 3.9 \\
\hline Day school & 582 & 87.1 & Father education & & \\
\hline Children live with & & & Not filled & 29 & 4.3 \\
\hline Parents & 638 & 95.5 & Illiterate & 3 & .4 \\
\hline Grandparents & 25 & 3.7 & Primary & 26 & 3.9 \\
\hline Other caregivers & 5 & .7 & Middle & 192 & 28.7 \\
\hline Ethnicity & & & High school & 100 & 15.0 \\
\hline Han & 586 & 87.7 & Diploma & 85 & 12.7 \\
\hline Other ethnic & 82 & 12.3 & Undergraduate & 161 & 24.1 \\
\hline Residence & & & Master & 44 & 6.6 \\
\hline Rural area & 504 & 75.4 & $\mathrm{PhD}$ & 28 & 4.2 \\
\hline Urban area & 164 & 24.6 & Mother profession & & \\
\hline Monthly Income (RMB) & & & Not filled & 26 & 3.89 \\
\hline$<3000$ & 80 & 12.0 & Farmer & 81 & 12.12 \\
\hline $3001-5000$ & 173 & 25.9 & Teacher & 94 & 14.07 \\
\hline $5001-10,000$ & 225 & 33.7 & Nurse & 13 & 1.95 \\
\hline$>10,000$ & 161 & 24.1 & Doctor & 23 & 3.44 \\
\hline Not filled & 29 & 4.3 & Civil servant & 34 & 5.1 \\
\hline Province & & & Private sector & 118 & 17.66 \\
\hline Gansu & 167 & 25.0 & Businessman & 32 & 4.09 \\
\hline Henan & 231 & 34.6 & Others & 247 & 36.98 \\
\hline Liaoning & 62 & 9.3 & Father profession & & \\
\hline Inner Mongolia & 72 & 10.8 & Not filled & 27 & 4.0 \\
\hline Zhejiang & 54 & 8.1 & Farmer & 73 & 10.9 \\
\hline Others & 82 & 12.27 & Teacher & 51 & 7.6 \\
\hline & & & Doctor & 19 & 2.8 \\
\hline
\end{tabular}


Table 1 Demographic characteristics of the respondents $(n=668)$ (Continued)

\begin{tabular}{|c|c|c|c|c|c|}
\hline \multicolumn{3}{|c|}{ Child Demographics } & \multicolumn{3}{|c|}{ Parents Demographics } \\
\hline Characteristics & Frequency & Percentage & Characteristics & Frequency & Percentage \\
\hline & & & Civil Servant & 59 & 8.8 \\
\hline & & & Private sector & 133 & 19.9 \\
\hline & & & Businessman & 55 & 8.2 \\
\hline & & & Others & 251 & 37.6 \\
\hline
\end{tabular}

\section{Discussion}

Implementations of public health emergency control measures have major impacts on the psychology of young children $[3,4]$. The negative consequences of COVID-19 pandemic is penetrating every aspects of the society, not only health but also economy, education, religion and politics $[16,17]$. Negative psychological effects are expected to happen and exacerbate when children are confined to their homes in the absence of outdoor activities and interpersonal communication with same aged friends [17-19]. It would be very common that they are feeling anxious, isolated and disappointed. In this study, we first quantified the effects of COVID-19 on mental health of children aged 7 to 15 years in China. We further identified important factors associated with the development of PTSD and depression symptoms. We found that 20.7 and $7.16 \%$ children experienced PSTD and depression symptoms due to the COVID-19 pandemic. The high prevalence rate of psychological symptoms in children is not surprising given the unprecedented negative effects of COVID-19 on everyone's daily lives. Children are confined at home, worrying about their education, and fearing the risk of contracting infection, and their families may suffer from substantial economic losses [3, 4, 20, 21]. Furthermore, the overwhelmed news reports and sensational news headlines related to COVID-19 have inevitably triggered worry, fear and anxiety among the general population including children $[3,21]$. These factors collectively and may synergistically affect the mental health of children.

PTSD and SMFQ-P scores are significantly higher in middle school and boarding school students compared to primary and day school students. Significantly higher PSTD and SMFQ-P scores in middle school students is probably related to their better awareness towards COVID-19, as SARS-CoV-2 is highly contagious [22]. Furthermore, they are more likely concerned about their studies and future plans $[4,23,24]$. In contrast, primary school children are not yet mature in childhood; therefore they are naturally less worried. Day school students

Table 2 Prevalence of PSTD (IES-R) and depression (SMFQ-P) symptoms among children aged 7 to 15 years

\begin{tabular}{|c|c|c|c|c|c|}
\hline & Total & PSTD (\%) & P-value & SMFQ-P (\%) & P-value \\
\hline Overall prevalence & 668 & 20.7 & & 7.2 & \\
\hline Education level & & & 0.05 & & 0.032 \\
\hline Primary & 394 & $71(18.0)$ & & $21(5.3)$ & \\
\hline Middle & 274 & $67(24.4)$ & & $27(9.8)$ & \\
\hline School type & & & 0.004 & & 0.02 \\
\hline Boarding school & 86 & $28(32.6)$ & & $12(13.9)$ & \\
\hline Day school & 582 & $110(18.9)$ & & $36(6.2)$ & \\
\hline Live with & & & 0.058 & & 0.18 \\
\hline Parents & 638 & $128(20.1)$ & & $44(6.9)$ & \\
\hline Grandparents & 25 & $7(28.0)$ & & $4(16.0)$ & \\
\hline Caregivers & 5 & $3(60.0)$ & & 0 & \\
\hline Province & & & 0.003 & & 0.44 \\
\hline Others & 82 & $23(28.0)$ & & $9(11.0)$ & \\
\hline Gansu & 167 & $29(17.4)$ & & $14(8.4)$ & \\
\hline Henan & 231 & $61(26.41$ & & $17(7.4)$ & \\
\hline Inner Mongolia & 62 & $9(14.5)$ & & $3(4.9)$ & \\
\hline Liaoning & 72 & $13(18.0)$ & & $3(4.2)$ & \\
\hline Zhejiang & 54 & $3(5.5)$ & & $2(3.7)$ & \\
\hline
\end{tabular}

PSTD: Post-traumatic stress disorder, SMFQ-P, Short Mood and Feeling questionnaire 
Table 3 Experience and attitudes towards online education

\begin{tabular}{llllll}
\hline Variables & No & Less & Average & Good & Excellent \\
\hline Effective & $51(7.6)$ & $321(48.0)$ & $211(31.6)$ & $65(9.73)$ & $20(3.0)$ \\
Efficient & $8(1.9)$ & $139(20.1)$ & $303(45.4)$ & $166(24.85)$ & $52(7.8)$ \\
Satisfied & $23(3.4)$ & $112(16.8)$ & $318(47.6)$ & $142(21.26)$ & $73(10.9)$ \\
\hline
\end{tabular}

and students living with parents have lower PSTD and SMFQ-P scores. This is consistent with previous studies that children living in institutions [25], children not living with parents, and orphans [26, 27] have higher risk developing psychological disorders.

In response to COVID-19, the Chinese government took strict measures; including school closure, travel ban, lockdown, and within-population quarantine. The Chinese New Year national holidays were extended but family visiting and social gathering were strictly banned [28]. Although control measures are universally implemented, the levels of intensity could still vary among different provinces, and between rural and urban areas. This may partially explain why students from different provinces and different resident areas have different degrees of psychological impact.

In response to school closure, the education sector has to suddenly switch to online learning. However, online education requires systematic thinking, design and implementation. But at this urgent circumstance especially China as the first epicenter, there was no sophisticated preparation, and the format of e-learning could vary dramatically among different regions and schools. Therefore, we could only perform a general assessment. Overall, a large proportion of respondents are stratified with online education. Children age, school level, provincial and residential background, and family income status are significantly associated with the effectiveness and satisfaction of the online education system. This can be explained by two main reasons. Children with old age
Table $\mathbf{5}$ Logistic regression analysis of factors accosted with the prevalence of PSTD symptoms

\begin{tabular}{|c|c|c|c|}
\hline Variables & Numbers & Sig. & $\mathrm{OD}(95 \% \mathrm{Cl})$ \\
\hline School level & & .097 & \\
\hline Primary & 394 & & 1 \\
\hline Middle & 274 & & $1.50(0.93-2.41)$ \\
\hline School type & & 0.05 & \\
\hline Boarding school & 86 & & 1 \\
\hline Day school & 582 & & $0.56(0.31-1.02)$ \\
\hline Children Live with & & 0.43 & \\
\hline Parents & 638 & & 1 \\
\hline Grand parents & 25 & & $1.41(0.56-3.55)$ \\
\hline Caregivers & 5 & & $3.03(0.41-22.65)$ \\
\hline Province & & 0.013 & \\
\hline Others & 82 & & 1 \\
\hline Gansu & 167 & & $0.48(0.24-0.94)$ \\
\hline Henan & 231 & & $0.63(0.33-1.22)$ \\
\hline Inner Mongolia & 62 & & $0.27(0.10-0.72)$ \\
\hline Liaoning & 72 & & $0.74(0.33-1.64)$ \\
\hline Zhejiang & 54 & & $0.15(0.042-0.55)$ \\
\hline \multicolumn{4}{|l|}{ Father Profession } \\
\hline Not fill & 27 & & 1 \\
\hline Farmer & 73 & & $1.45(0.53-4.08)$ \\
\hline Teacher & 51 & & $0.78(0.24-2.50)$ \\
\hline Doctor & 19 & & $1.2(0.29-4.97)$ \\
\hline Civil servant & 59 & & $0.54(0.16-1.78)$ \\
\hline Private sector & 133 & & $0.64(0.23-1.78)$ \\
\hline Businessman & 55 & & $0.31(0.09-1.09)$ \\
\hline Others & 251 & & $0.72(0.28-1.86)$ \\
\hline
\end{tabular}

OD: Odd ratio, Cl: Confidence interval

Variable(s) entered on step 1: school level, school type, child living with whom, province, father profession

Table 4 Correlation between online education variables, IES-R, MFQ-P and demographic characteristics

\begin{tabular}{|c|c|c|c|c|c|c|c|c|c|c|}
\hline & & Sex & Age & School level & School type & Child live with whom & Province & Ethnicity & Residence & Income/M \\
\hline \multirow[t]{2}{*}{ Effectiveness } & Pearson $r$ & .041 & $.149^{* *}$ & $.172^{* *}$ & -.037 & .007 & .040 & -.071 & $-.105^{* *}$ & -.004 \\
\hline & Sig (2-tailed) & .295 & .000 & .000 & .338 & .857 & .302 & .065 & .007 & .923 \\
\hline \multirow[t]{2}{*}{ Efficiency } & Pearson $r$ & .055 & $.202^{* *}$ & $229^{* *}$ & -.027 & .047 & $.106^{* *}$ & -.047 & $-.113^{* *}$ & -.022 \\
\hline & Sig (2-tailed) & .156 & .000 & .000 & .483 & .223 & .006 & .223 & .004 & .566 \\
\hline \multirow[t]{2}{*}{ Satisfaction } & Pearson $r$ & .030 & $.173^{* *}$ & $.166^{* *}$ & -.045 & .032 & $.078^{*}$ & $-.077^{*}$ & -.037 & $-.102^{* *}$ \\
\hline & Sig (2-tailed) & .440 & .000 & .000 & .247 & .410 & .043 & .047 & .339 & .008 \\
\hline \multirow[t]{2}{*}{ IES-R-P total } & Pearson $r$ & -.022 & .047 & .052 & $-.106^{* *}$ & $.078^{*}$ & $-.093^{*}$ & -.028 & $.100^{* *}$ & $-.101^{* *}$ \\
\hline & Sig (2-tailed) & .576 & .221 & .179 & .006 & .044 & .016 & .477 & .009 & .009 \\
\hline \multirow[t]{2}{*}{ SMFQ-P score } & Pearson $r$ & -.029 & $.111^{* *}$ & $.100^{*}$ & $-.130^{* *}$ & .057 & $-.093^{*}$ & -.013 & $.083^{*}$ & -.058 \\
\hline & Sig (2-tailed) & .459 & .004 & .010 & .001 & .141 & .016 & .729 & .032 & .136 \\
\hline
\end{tabular}

IES-R, Impact of Event Scale-Revised, MFQ-P, Mood and Feeling questionnaire-parents * $p<0.05$ 
are technically more capable of adapting to this new form of education. Families or regions with higher socioeconomic status are more accessible to high technologies and digital devices. Thus, there are still a substantial proportion of students who are not comfortable with online education and are not participating effectively. The education sectors and other stakeholders should pay attention to optimize the education program and ensure equal access to the technology and tools. Effective and universally accessible online education will not only minimize academic loss, but also mitigate the mental health of children by actively involving teachers, parents and friends.

Of note, there are some limitations in this study. First, the survey was invited via the WeChat app based on social network. This may lead to bias, but our respondents are widely distributed across different parts of China with different background. Second, due to the nature of online survey, we could only use self-reporting instead of diagnostic interview for assessing psychiatric morbidity. Last but not the least; we could not study the content of online education in detailed, as the format varies dramatically among different regions and schools in China.

\section{Conclusion}

In summary, we found that 20.7 and $7.16 \%$ of children aged 7 to 15 years in China experienced psychological issues due to the COVID-19 epidemic. These symptoms are more prevalent in middle school and boarding school students compared to primary and day school students. In general, a large proportion of respondents are satisfied with online education, but still a substantial proportion of students are not comfortable with this new form of learning. Therefore, authorities should continuously optimize the online education program and ensure equal access to digital learning opportunities.

\section{Appendix 1}

Table 6 Responses to different questions related to knowledge and overall effects of COVID-19 $(n=668)$

\begin{tabular}{llll}
\hline & Yes & Percentage \\
\hline Is your family well-aware of COVID-19? & 562 & 84.1 \\
Are your child back to routine after the control of & 489 & 73.2 \\
COVID-19 epidemic? & 183 & 27.4 \\
COVID-19 affected your child physically & 312 & 46.7 \\
COVID-19 affected your child psychologically & 239 & 35.8 \\
COVID-19 affected your child emotionally & 227 & 34 \\
COVID-19 affected your child socially & 250 & 37.4 \\
COVID-19 did not affected your child & &
\end{tabular}

Table 7 Logistic regression analysis on factors associated with the prevalence of depressive symptoms.

\begin{tabular}{llll}
\hline & Numbers & Sig. & OD( 95\% Cl) \\
\hline School level & & 0.16 & \\
Primary & 394 & & 1 \\
Middle & 274 & & $1.59(0.83-3.05)$ \\
School type & & 0.09 & \\
Boarding school & 86 & & 1 \\
Day school & 582 & & $0.51(0.24-1.11)$ \\
\hline
\end{tabular}

OR: odd ratio, $\mathrm{Cl}$ : Confidence Interval

\section{Abbreviations}

PTSD: Post-traumatic stress disorder; COVID-19: Coronavirus disease 2019; SMFQ-O: Mood and Feeling questionnaire-parents; IES-R: Impact of Events Scale-Revised; OR: Odds ratio; Cl: Confidence interval

\section{Acknowledgments}

We sincerely thank all the participants who took part in this study.

\section{Authors' contributions}

All authors contributed to the concept of this study. PQ, MZ, and ZB designed the study. YJ, SI, YZ, ZB, AW and ZL acquired and analyzed data. $Z B, S I$ and QP wrote the manuscript. All the authors reviewed and approved the final manuscript.

\section{Funding}

The work was supported by the Ministry of Education of China for an Innovative Research Team in University grant (No. IRT_17R88; to Z.M.) and partical supported by grant from National Natural Science Foundation of China (No. 82041005). The funders had no role in study design, data collection and interpretation, or the decision to submit the work for publication.

\section{Availability of data and materials}

The datasets generated and analyzed during the current study are not publicly available due to the risk of compromising the individual privacy of participants, but are available from the corresponding author on reasonable request.

\section{Ethics approval and consent to participate}

The Institutional Review ethical committee of Northwest Minzu University reviewed and approved the protocol used in this study (BMRC-2020-1).

Written linformed consent was individually obtained from the parents.

\section{Consent for publication}

Consent was obtained from the parents of every individual whose data are included in this manuscript.

\section{Competing interests}

All author declare No competing interests.

\section{Author details \\ ${ }^{1}$ China-Malaysia National Joint Laboratory, Biomedical Research Center, Northwest Minzu University, Lanzhou, China. ${ }^{2}$ Department of Psychiatry, Faculty of Medicine, Universiti Teknologi MARA, Shah Alam, Selangor, Malaysia. ${ }^{3}$ Faculty of Life Science and Technology, Kunming University of Science and Technology, Kunming 650500, Yunnan, China. ${ }^{4}$ Department of Gastroenterology and Hepatology, Erasmus MC-University Medical Center, Rotterdam, the Netherlands.}

Received: 2 July 2020 Accepted: 10 February 2021

Published online: 24 February 2021

\section{References}

1. The Lancet Child Adolescent H. Pandemic school closures: risks and opportunities. Lancet Child Adolesc Health 2020, 4(5):341. 
2. Ursano RJ, Zhang L, Li H, Johnson L, Carlton J, Fullerton CS, Benedek DM. PTSD and traumatic stress from gene to community and bench to bedside. Brain Res. 2009;1293:2-12.

3. Dalton L, Rapa E, Stein A. Protecting the psychological health of children through effective communication about COVID-19. Lancet Child Adolesc Health. 2020;4(5):346-7.

4. Wang G, Zhang Y, Zhao J, Zhang J, Jiang F. Mitigate the effects of home confinement on children during the COVID-19 outbreak. Lancet. 2020; 395(10228):945-7.

5. Kwok KO, Wong V, Wei WWI, Wong SYS, Tang JW. Novel coronavirus (2019$\mathrm{nCoV}$ ) cases in Hong Kong and implications for further spread. J Inf Secur. 2020.

6. Beck JG, Grant DM, Read JP, Clapp JD, Coffey SF, Miller LM, Palyo SA. The impact of event scale-revised: psychometric properties in a sample of motor vehicle accident survivors. J Anxiety Disord. 2008;22(2):187-98.

7. Wilson JP, Tang CS-k. Cross-cultural assessment of psychological trauma and PTSD. New York: Springer; 2007.

8. Horowitz M, Wilner N, Alvarez W. Impact of event scale: a measure of subjective stress. Psychosom Med. 1979;41(3):209-18.

9. Joseph S. Psychometric evaluation of Horowitz's impact of event scale: a review. J Trauma Stress. 2000;13(1):101-13.

10. Chong MY, Wang WC, Hsieh WC, Lee CY, Chiu NM, Yeh WC, Huang OL, Wen JK, Chen CL. Psychological impact of severe acute respiratory syndrome on health workers in a tertiary hospital. Br J Psychiatry. 2004;185: 127-33.

11. Hsu CC, Chong MY, Yang P, Yen CF. Posttraumatic stress disorder among adolescent earthquake victims in Taiwan. J Am Acad Child Adolesc Psychiatry. 2002;41(7):875-81.

12. Angold A, Costello EJ, Messer SC, Pickles A. Development of a short questionnaire for use in epidemiological studies of depression in children and adolescents. Int J Methods Psychiatr Res. 1995;5(4):237-49.

13. Costello EJ, Angold A. Scales to assess child and adolescent depression: checklists, screens, and nets. J Am Acad Child Adolesc Psychiatry. 1988;27(6); 726-37.

14. Kuo ES, Stoep AV, Stewart DG. Using the short mood and feelings questionnaire to detect depression in detained adolescents. Assessment. 2005;12(4):374-83.

15. Turner N, Joinson C, Peters TJ, Wiles N, Lewis G. Validity of the short mood and feelings questionnaire in late adolescence. Psychol Assess. 2014;26(3): 752-62.

16. Brooks SK, Webster RK, Smith LE, Woodland L, Wessely S, Greenberg N, Rubin GJ. The psychological impact of quarantine and how to reduce it: rapid review of the evidence. Lancet. 2020;395(10227):912-20.

17. Cao W, Fang Z, Hou G, Han M, Xu X, Dong J, Zheng J. The psychological impact of the COVID-19 epidemic on college students in China. Psychiatry Res. 2020;287:112934.

18. Kmietowicz Z. Rules on isolation rooms for suspected covid-19 cases in GP surgeries to be relaxed. Bmj-Brit Med J. 2020;368.

19. Xiao C. A novel approach of consultation on 2019 novel coronavirus (COVID-19)-related psychological and mental problems: structured letter therapy. Psychiatry Investig. 2020;17(2):175-6.

20. Bao Y, Sun Y, Meng S, Shi J, Lu L. 2019-nCoV epidemic: address mental health care to empower society. Lancet. 2020;395(10224):e37-8.

21. Ayittey FK, Ayittey MK, Chiwero NB, Kamasah JS, Dzuvor C. Economic impacts of Wuhan 2019-nCoV on China and the world. J Med Virol. 2020; 92(5):473-5.

22. Song ZQ, Xu YF, Bao LL, Zhang L, Yu P, Qu YJ, Zhu H, Zhao WJ, Han YL, Qin C. From SARS to MERS, Thrusting Coronaviruses into the Spotlight. VirusesBasel. 2019;11(1)

23. Cornine A. Reducing nursing student anxiety in the clinical setting: an integrative review. Nurs Educ Perspect. 2020.

24. Wang C, Horby PW, Hayden FG, Gao GF. A novel coronavirus outbreak of global health concern. Lancet. 2020;395(10223):470-3.

25. Desmond C, Watt K, Saha A, Huang J, Lu C. Prevalence and number of children living in institutional care: global, regional, and country estimates. Lancet Child Adolesc Health. 2020;4(5):370-7.

26. Woodgate RL, Tailor K, Tennent P, Wener P, Altman G. The experience of the self in Canadian youth living with anxiety: a qualitative study. PLoS One. 2020;15(1):e0228193.

27. Gentili D, Bardin A, Ros E, Piovesan C, Ramigni M, Dalmanzio M, Dettori M Filia A, Cinquetti S. Impact of Communication Measures Implemented
During a School Tuberculosis Outbreak on Risk Perception among Parents and School Staff, Italy, 2019. Int J Env Res Pub He. 2020:17(3).

28. Tang B, Wang X, Li Q, Bragazzi NL, Tang S, Xiao Y, Wu J. Estimation of the Transmission Risk of the 2019-nCoV and Its Implication for Public Health Interventions. J Clin Med. 2020:9(2).

\section{Publisher's Note}

Springer Nature remains neutral with regard to jurisdictional claims in published maps and institutional affiliations.
Ready to submit your research? Choose BMC and benefit from:

- fast, convenient online submission

- thorough peer review by experienced researchers in your field

- rapid publication on acceptance

- support for research data, including large and complex data types

- gold Open Access which fosters wider collaboration and increased citations

- maximum visibility for your research: over $100 \mathrm{M}$ website views per year

At $\mathrm{BMC}$, research is always in progress.

Learn more biomedcentral.com/submissions 